\title{
Phytochemical and biological investigation of Indian plant of givotia rottlerifromis griff
}

\author{
V. Mohanraj ${ }^{1,3, *}$, R.V. Sakthivel ${ }^{2}$, M. Karthick ${ }^{1}$, R. Velmurugan ${ }^{4}$ \\ ${ }^{1}$ Sri Ramakrishna Mission Vidyalaya College of Arts and Science, Coimbatore - 641 020, Tamil Nadu, India \\ ${ }^{2}$ Arignar Anna Government Arts College, Namakkal-637 002, Tamil Nadu, India \\ ${ }^{3}$ Manonmaniam Sundaranar University, Constituent College, Kanyakumari - 629 401, Tamil Nadu, India \\ ${ }^{4}$ Department of Chemistry, Kongunadu Arts and Science College, Coimbatore - 641029, Tamil Nadu, India \\ ${ }^{*}$ Corresponding author: chemistrymohan@gmail.com
}

DOI: https://doi.org/10.34256/irimt2129

Received: 02-03-2021, Revised: 15-03-2021, Accepted: 17-03-2021, Published: 22-03-2021

Abstract: A study on givotia rottlerifomis griff shows that studies on a tremendous of pharmacological and physiological activities and other applications. Moreover, givotia rottlerifomis griff has diverse physiological effects. This tempted us to use the bark of givotia rottlerifomis griff for extraction of new compound from the extract. Attempt is made to develop an efficient method for isolation of compounds from the barks of givotia rottlerifomis griff. Our scheme of work is to separate a portion by treatment with pure methanol $(\mathrm{CH} 3 \mathrm{OH})$ using soxhlet apparatus at boiling temperature and the sample is crystallized to separate to the pure compound. The compound was identified further by chromatographic studies, melting point determination, and spectral analysis (IR, 1D and 2D NMR) etc. Furthermore, antimicrobial studies are tested various antibacterial and antifungal species and also molecular docking studies are checked with HIV protease with Schrodinger 9.5 software.

Keywords: Givotia rottlerifomis griff, Soxhlet apparatus,1D and 2D NMR, Molecular docking studies.

\section{Introduction}

A natural product is a chemical compound or substance produced by a living organism that is found in nature. In the broadest sense natural products include any substance produced by life [1]. Natural products can also be prepared by chemical synthesis (both semi synthesis and total synthesis) and have played a central role in the development of the field of organic chemistry by providing challenging synthetic targets [2]. The term natural product has also been extended for commercial purposes to refer to cosmetics, dietary supplements, and foods produced from natural sources without added artificial ingredients [3].

Within the field of organic chemistry, the definition of natural products is usually restricted to mean purified organic compounds isolated from natural sources that are produced by the pathways of primary or secondary metabolism [4,5]. Within the field of medicinal chemistry, the definition is often further restricted to secondary metabolites $[6,7]$ Secondary metabolites are not essential for survival, but nevertheless provide organisms that produce them an evolutionary advantage $[8,9]$. Many secondary metabolites are cytotoxic and have been selected and optimized through evolution for use as "chemical warfare" agents against prey, predators, and competing organisms [10-15].

In the present investigation new compound has been extracted from the givotia rottlerifomis griff and screened for its chemical and pharmacological activities.

\section{Experimental methods}

\subsection{Plant Material}

This plant material is available in Tamil Nadu, Karnataka, Andhra Pradesh and Srilanka. The bark is collected from Kanjamalai (Namakkal). The barks used for the study were cleaned manually to free them from stones and other undesirable matter and then ground in an electrically operated grinder to fine particle size.

\subsection{Chemicals}

All chemicals were analytical grade expect petroleum ether $\left(60-80^{\circ} \mathrm{C}\right)$, Ethyl acetate, methanol, Silica gel for TLC, Silica gel for Column and ethanol was of laboratory grades. Except ethanol all other solvents were purchased from Merck chemicals 
private Ltd. (India).

A Soxhlet extractor is a piece of laboratory apparatus invented in 1879 by Franz von Soxhlet. It was originally designed for the extraction of a lipid from a solid material. However, a Soxhlet extractor is not limited to the extraction of lipids. Typically, a Soxhlet extraction is only required where the desired compound has a limited solubility in a solvent, and the impurity is insoluble in that solvent. If the desired compound has a significant solubility in a solvent then a simple filtration can be used to separate the compound from the insoluble substance. Normally a solid material containing some of the desired compound is placed inside a thimble made from thick filter paper, which is loaded into the main chamber of the Soxhlet extractor. The Soxhlet extractor is placed onto a flask containing the extraction solvent. The Soxhlet is then equipped with a condenser. The solvent is heated to reflux. The solvent vapour travels up a distillation, and floods into the chamber housing the thimble of solid. The condenser ensures that any solvent vapour cools, and drips back down into the chamber housing the solid material.

The chamber containing the solid material slowly fills with warm solvent. Some of the desired compound will then dissolve in the warm solvent. When the Soxhlet chamber is almost full, the chamber is automatically emptied by a siphon side arm, with the solvent running back down to the distillation flask. This cycle may be allowed to repeat many times, over hours or days. During each cycle, a portion of the nonvolatile compound dissolves in the solvent. After many cycles the desired compound is concentrated in the distillation flask. The advantage of this system is that instead of many portions of warm solvent being passed through the sample, just one batch of solvent is recycled. After extraction the solvent is removed, typically by means of a rotary evaporator, yielding the extracted compound. The non-soluble portion of the extracted solid remains in the thimble, and is usually discarded. The concentrate extract was involved to column chromatographic technique.

\subsection{Chemicals Test}

\subsubsection{Test for Nitrogen element}

The pure compound was taken for the analysis for the analysis of elements by standard methods and it was found that Nitrogen is present as a special element. A small quantity of the sample is added with sodium metal is taken in a fusion tube. It is made alkaline by adding 2-3 drops of sodium hydroxide $(\mathrm{NaOH})$ solution. $1 \mathrm{~mL}$ of freshly prepared solution of ferrous sulphate is added to this solution. The mixture of the two solutions is boiled and then acidified with dilute sulphuric acid. The Prussian blue coloration of the precipitate is obtained. It confirms the presence of nitrogen in the compound.

\subsection{Tests for Unsaturation}

The test of unsaturation by alkaline $\mathrm{KMnO}_{4}$ method showed the presence of unsaturation in the compound. A small amount of the compound is treated with small quantity of sodium carbonate solution and very dilute solution of $\mathrm{KMnO}_{4}$. The pink colour is decolourised. It confirms the presence of unsaturation in the compound.

\subsection{Column Chromatographic Analysis}

In column chromatography the powdered adsorbent (silica gel) is placed in a vertical glass tube. The extract is added to the top of the column. A solvent (methanol) is then allowed to flow down the tube separation of the components of the extract takes place as a result single adsorption. The compound is visible, coloured band appear down the column. The flow of the solvent is continued until all the compound is eluted from the bottom. The pure single compound is obtained and dried.

\subsection{Thin-Layer Chromatographic Analysis}

Transfer a small portion of the purified sample and dissolve them in a few drops of ethyl acetate. Prepare a silica gel thin-layer chromatography plate for the spotting of sample. With the aid of a capillary, place a sample of the crude oil remaining from the extraction procedure, a sample of the filtrate from the isolation procedure, the sample prepared from the purified chemical compound, and a sample of a chemical compound standard on separate points of the thin-layer plate. Develop the plate using 3:2 Petroleum ether \& ethyl acetate. Visualize under in an iodine chamber. A single spot is appeared in TLC.

\subsection{Other Characterizations}

Melting points were recorded with melting point apparatus Macro Scientific Works found to be $164^{\circ} \mathrm{C}$. The percentage of yield is $30 \%$. Thin Layer Chromatography (TLC) was performed on glass plates coated with silica gel 60 (E. Merck, India Ltd.) and column chromatography technique was isolated for pure single compounds with silica gel. FT IR spectrum was recorded employing Brucker FT- IR spectrometer. The $1 \mathrm{H} \mathrm{NMR}$ and 13C NMR spectra of the compound were recorded using the $\mathrm{AMX} 500 \mathrm{MHz}$ Bruker spectrometer with DMSO as the internal standard reference. The $1 \mathrm{H}-1 \mathrm{H}$ COSY and $13 \mathrm{C}-1 \mathrm{H}$ COSY spectrum of the compound were recorded using the AMX $500 \mathrm{MHz}$ Bruker spectrometer with DMSO as the internal standard reference. In vitro antimicrobial activity was examined for various alcoholic extract of plant of the study species against four bacterial and four fungal species. Molecular docking studies of the isolated compound was docked in to the active site of 
the HIV Protease (PDB ID: 1HXW) using Glide from Schrodinger 9.5 .

\section{Results and Discussion}

\subsection{Spectral analysis}

The Givotia rottleriformis griff (Venthal tree) bark extract contains several important olefinic compounds. The olefinic compounds are important in motional biology. In the present work we have attempted to bark extract an important component from by solvent extraction procedure. In our experiment we have selected solvent such as methanol throughout the extraction process. Extracted product was isolated, purified and identified by TLC, column, FT-IR, ${ }^{1} \mathrm{H}$ NMR, ${ }^{13} \mathrm{C}$ NMR and COSY $\left({ }^{1} \mathrm{H}-{ }^{-1} \mathrm{H},{ }^{13} \mathrm{C}-{ }^{-1} \mathrm{H}\right)$ NMR spectra.

\subsection{FT-IR spectrum of the compound}

The FT-IR spectrum of the compound is shown figure 1 . IR data reveals that the compound consist cyclic ring, double bond, and hydroxyl and amine functional group. In this spectrum to given some important idea of the found the structure. The absorption frequency of the olefinic in conjugation with some functional group is also lower by the $400 \mathrm{~cm}$. ${ }^{1} \approx 1610 \mathrm{~cm}^{-1}$ the intensity of absorption is increased on conjugation of an olefinic double bond the $\mathrm{C}=\mathrm{C}$ stretch is lowered and the intensity of absorption increased. Resonance result in partial $\pi$ bond character between the two double bonds therefore vibrate at lower frequency these do similar isolated double bond. In the region of $3385 \mathrm{~cm}^{-1}$ and $3237 \mathrm{~cm}^{-}$ 1. we have to find out the main point of $\mathrm{O}-\mathrm{H}$ stretching and $\mathrm{N}-\mathrm{H}$ stretching vibration respectively. The N-H stretching of hydrogen bonded primary amine coupled doublet in broad peak rang $3237 \mathrm{~cm}^{-1}$.

\section{3 ${ }^{1} \mathrm{H}$ and ${ }^{13} \mathrm{C}-\mathrm{NMR}$ Spectrum of the isolated compound}

The ${ }^{1} \mathrm{H}$ NMR ( $\left.\delta \mathrm{ppm}\right)$ spectrum was recorded in $500 \mathrm{MHz}$ Brucker instrument. The NMR result again confirms the purity of the compound. It is also indicating 10 proton of olefinic regions of 3 to $6 \mathrm{ppm}$. The proton NMR spectrum of compound (Figures 2, 3 \& 4) as only $A B X$ system for the hetero cyclic ring proton $\left(\mathrm{H}_{3} \mathrm{a}, \mathrm{H}_{2} \mathrm{a}\right.$ and $\left.\mathrm{H}_{2} \mathrm{e}\right)$ and $\left(\mathrm{H}_{4} \mathrm{a}, \mathrm{H}_{5} \mathrm{a}\right.$ and $\left.\mathrm{H}_{5} \mathrm{e}\right)$. Since no coupling partner is available at C3-C4 proton. The olefinic methyl analog indicated the axial position for the proton and equatorial orientation for the methyl protons groups. The signle at $4.4 \mathrm{ppm}$ with ${ }^{3} \mathrm{~J}$ value of $12 \mathrm{~Hz} \mathrm{~J}\left(\mathrm{H}_{5} \mathrm{a}, \mathrm{H}_{4} \mathrm{e} \& \mathrm{H}_{4} \mathrm{e}, \mathrm{H}_{5} \mathrm{e}\right)$ and $\mathrm{J} 5 \mathrm{e}, 4 \mathrm{e}-3 \mathrm{~Hz}$ is assigned to the axial proton at $\mathrm{HC}=\mathrm{CH}$ and it conformed the equatorial orientation of $\mathrm{C} 2$ and $\mathrm{C} 5$ groups. The presence of $\mathrm{N}-\mathrm{H}$ proton and $\mathrm{O}-\mathrm{H}$ proton at $2.93 \mathrm{ppm}$ and $4.6 \mathrm{ppm}$ respectively. A mass spectrum of this compound the presence of at $\mathrm{M}^{+}$ion at $\mathrm{m} / \mathrm{e} 99$ and the fragmentation pattern conform the structure of the isolated compound. In the ${ }^{13} \mathrm{C}$ NMR $(\delta \mathrm{ppm})$ spectrum (Figure 5$)$ the ranges of carbon atom appear between 72.3 \& $75.7 \mathrm{ppm}$, suggesting only an olefinic unsaturated carbon atoms are present.

\subsection{D NMR (COSY)spectrum of the compound}

The structure of the compound also confirmed by correlation spectra ${ }^{1} \mathrm{H}-{ }^{-1} \mathrm{H}$ COSY and ${ }^{1} \mathrm{H}-{ }^{13} \mathrm{C}$ COSY (Figures 6, $7 \& 8$ ). Tentative proposed structure of the isolated compound. DEPT - 135 spectrums also to find out odd and even carbon to help of find the structure (Figures $9 \& 10$ ).

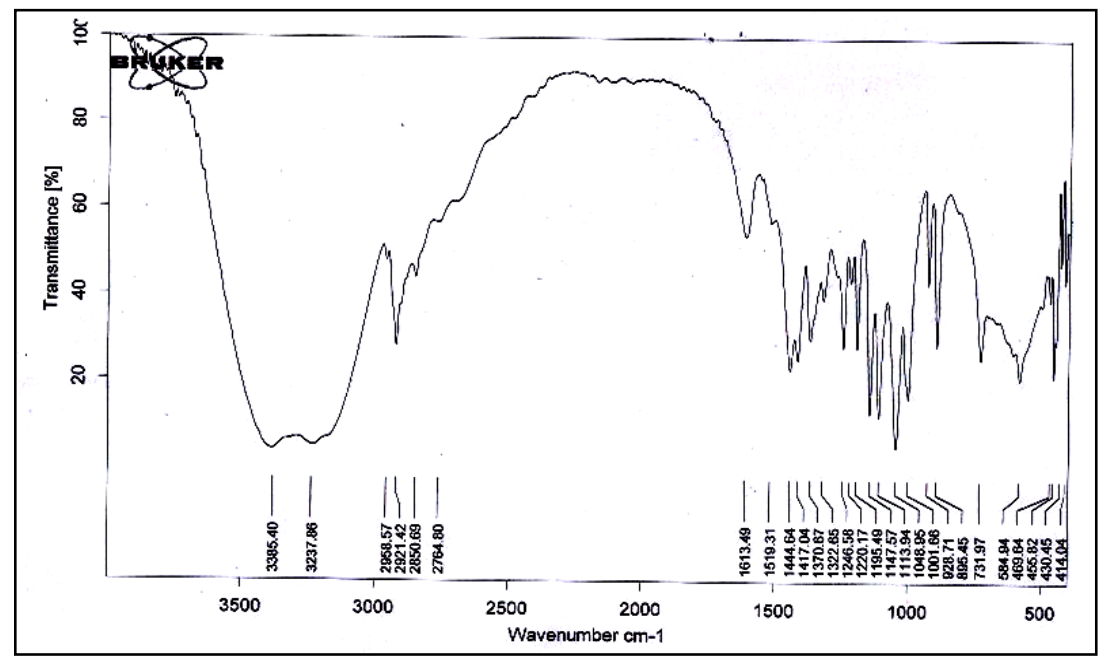

Figure 1. FT- IR spectra of the $N$ - cyclopent-1-enyl-hydroxylamine 


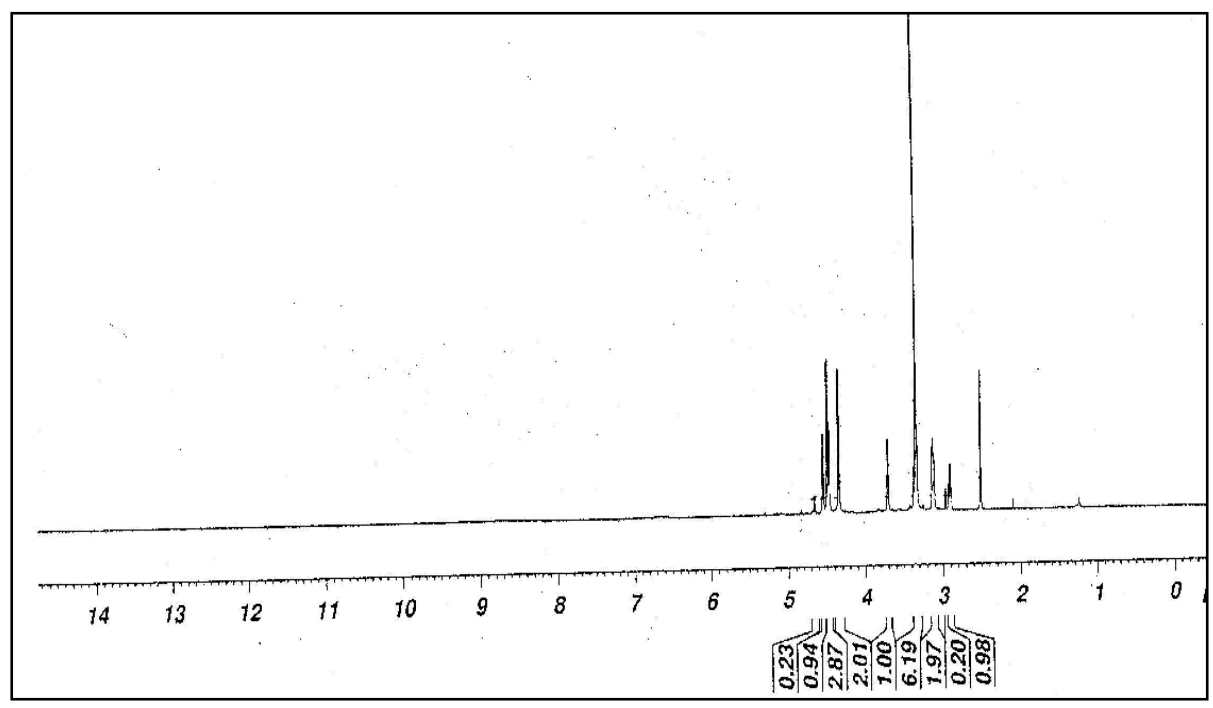

Figure 2. ${ }^{1} \mathrm{H}$ NMR spectra of the $\mathrm{N}$ - cyclopent-1-enyl-hydroxylamine

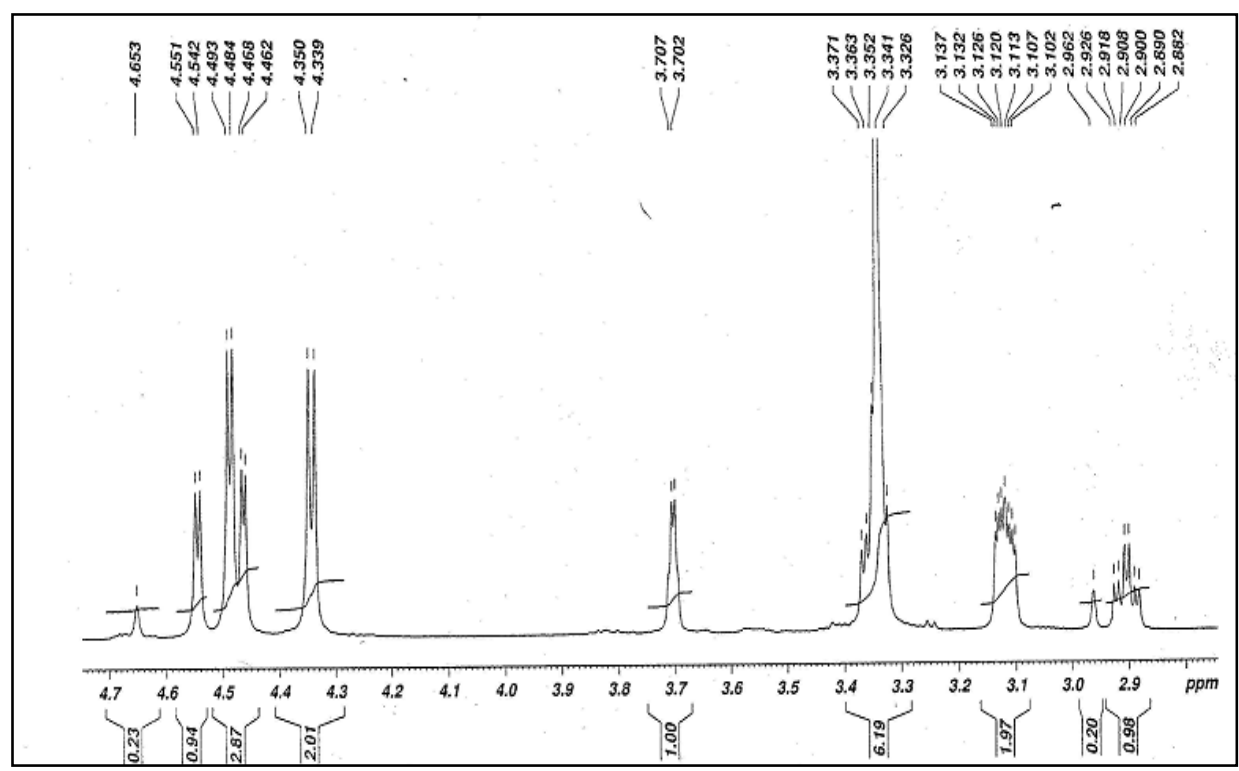

Figure 3. ${ }^{1} \mathrm{H}$ NMR spectra of the $\mathrm{N}$ - cyclopent-1-enyl-hydroxylamine

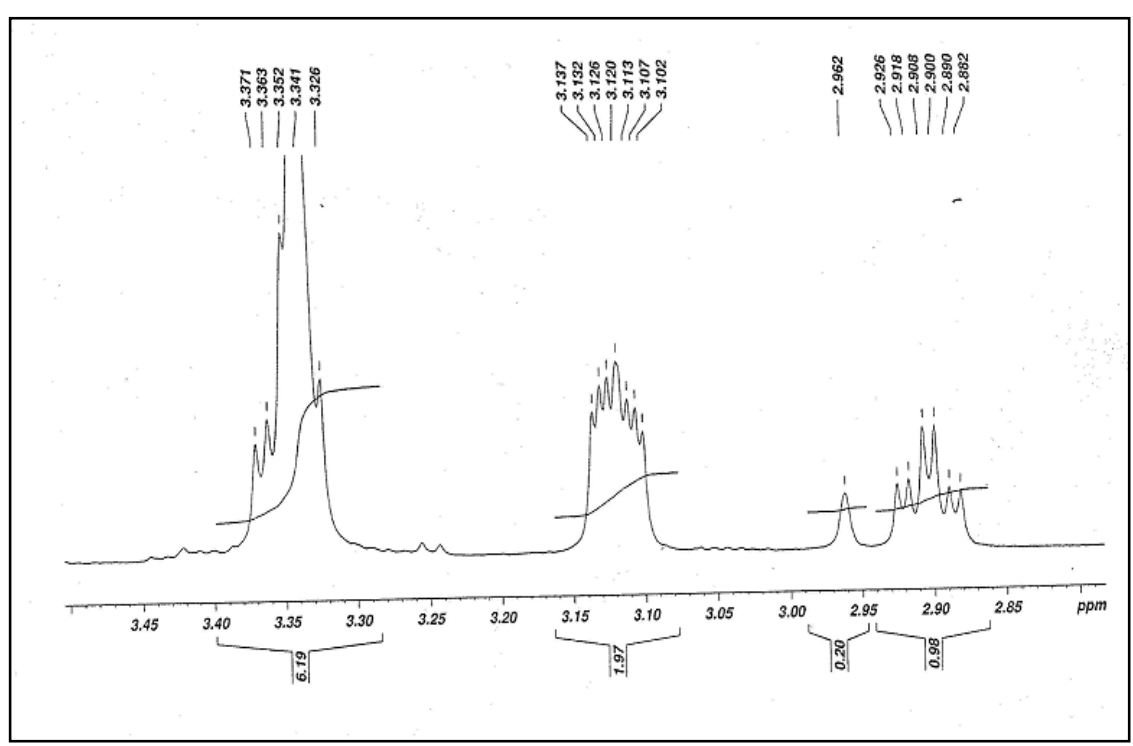

Figure 4. ${ }^{1} \mathrm{H}$ NMR [Ex] spectra of the $\mathrm{N}$ - cyclopent-1-enyl-hydroxylamine 


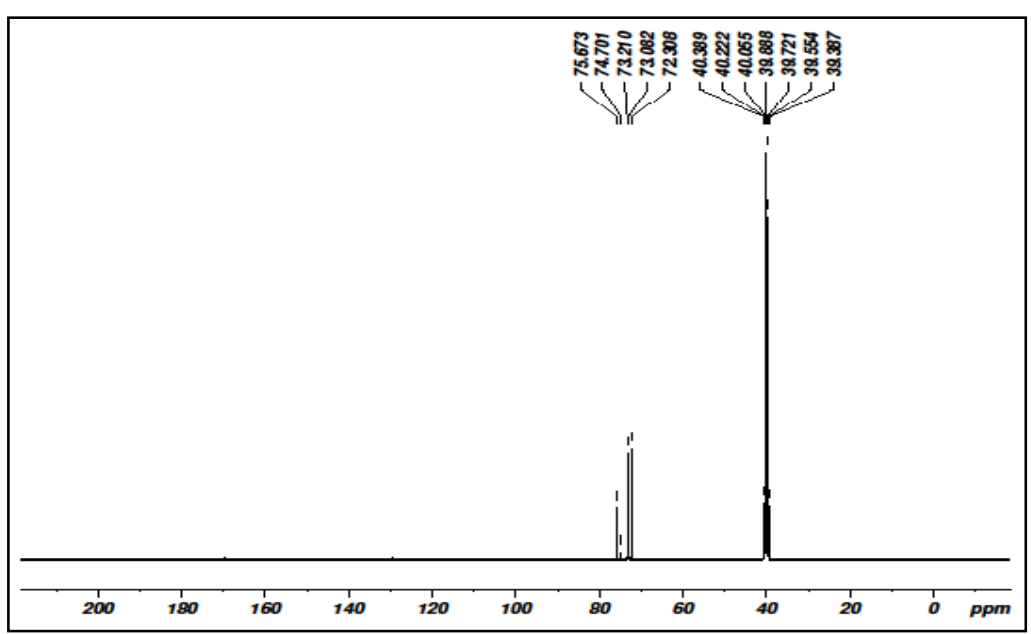

Figure $5{ }^{13} \mathrm{C}$-NMR spectra of the $\mathrm{N}$ - cyclopeny-1-enyl-hydroxylamine

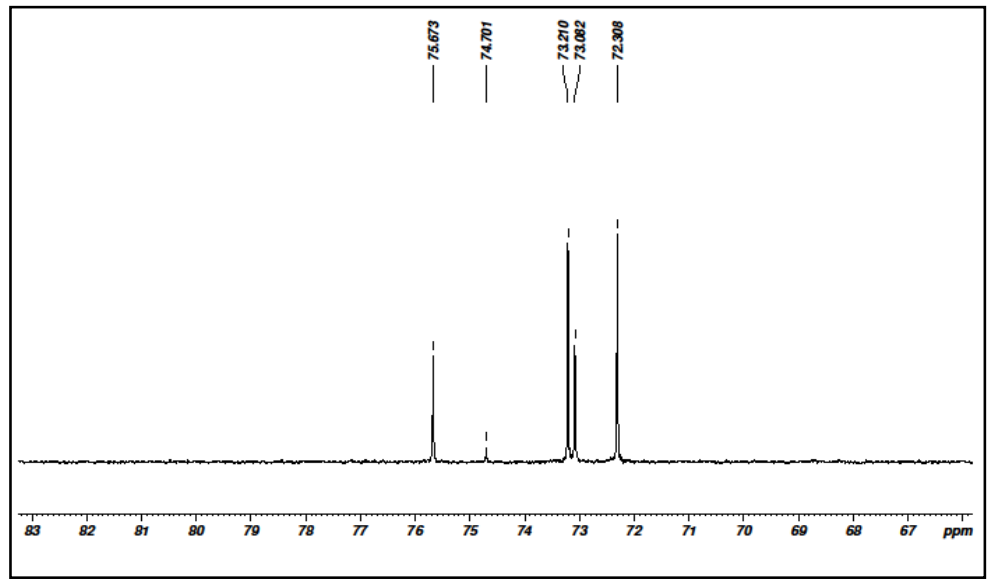

Figure $6{ }^{13} \mathrm{C}$-NMR[Ex] spectra of the $\mathrm{N}$-cyclopent1-enyl-hydroxylamine

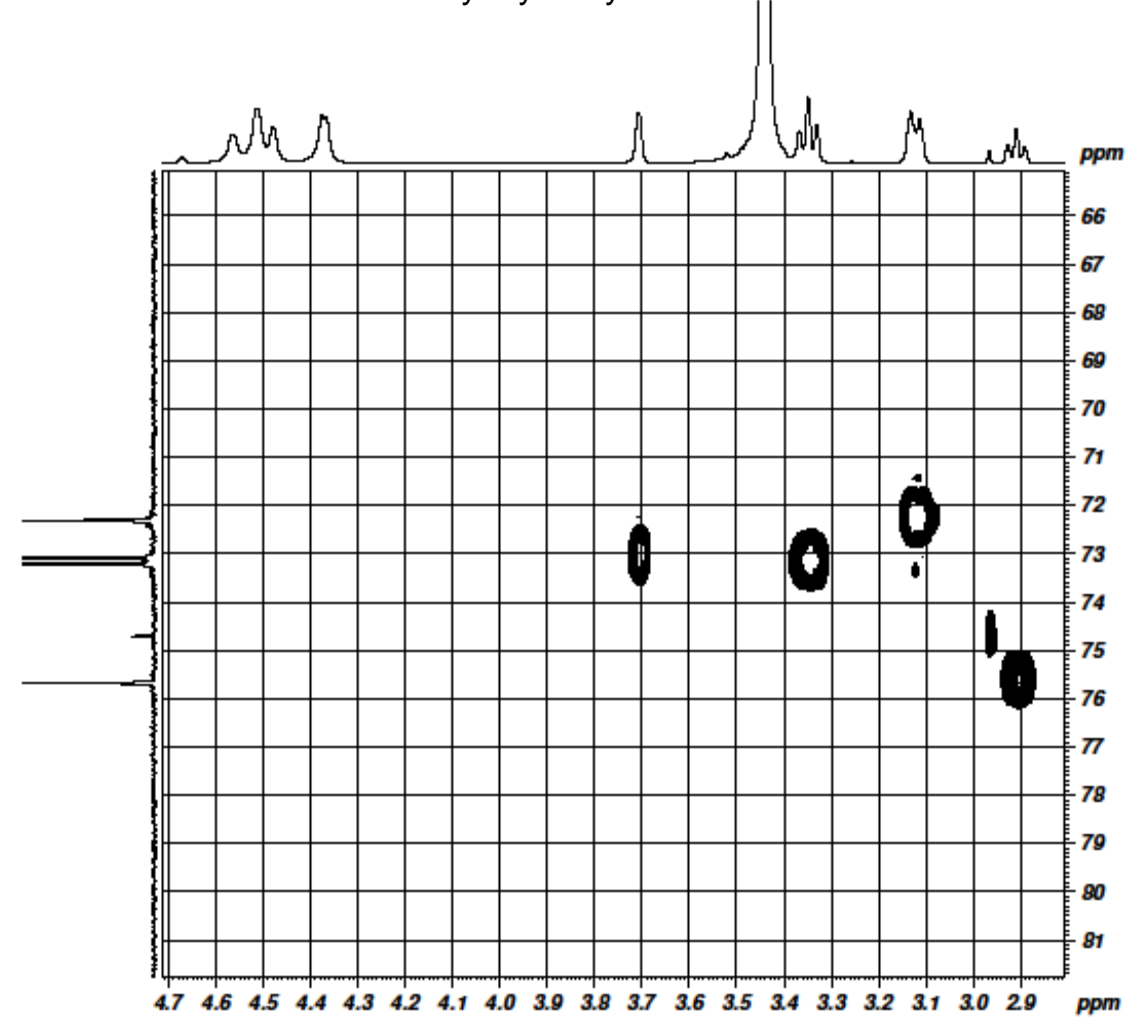

Figure $7{ }^{1} \mathrm{H}-{ }^{13} \mathrm{C}$ COSY NMR spectra of the $\mathrm{N}$-cyclopent-1-enyl-hydroxylamine 


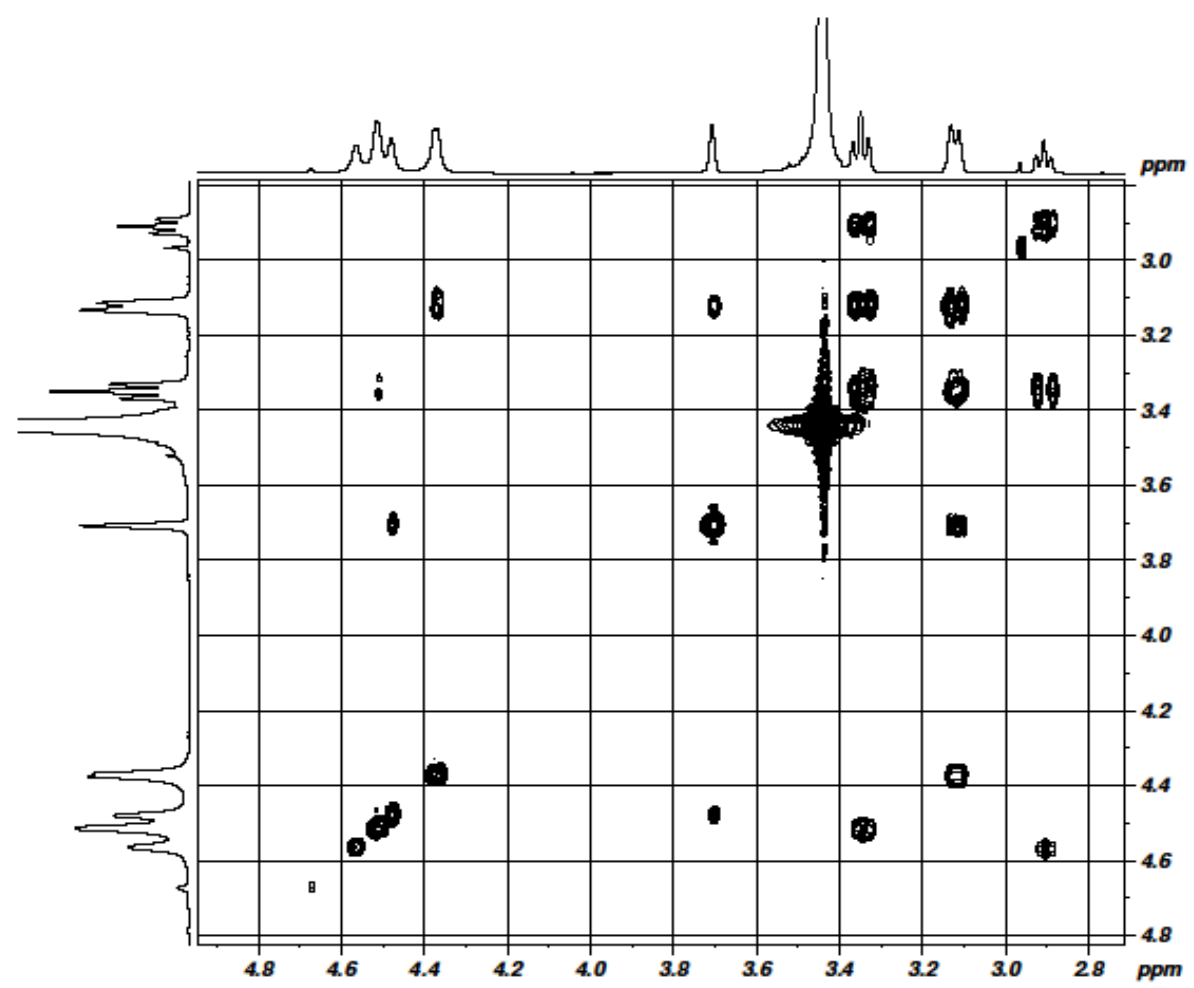

Figure $8{ }^{1} \mathrm{H}-{ }^{1} \mathrm{H}$ COSY NMR [Ex] spectra of the $\mathrm{N}$-cyclopent-1-enyl-hydroxylamine

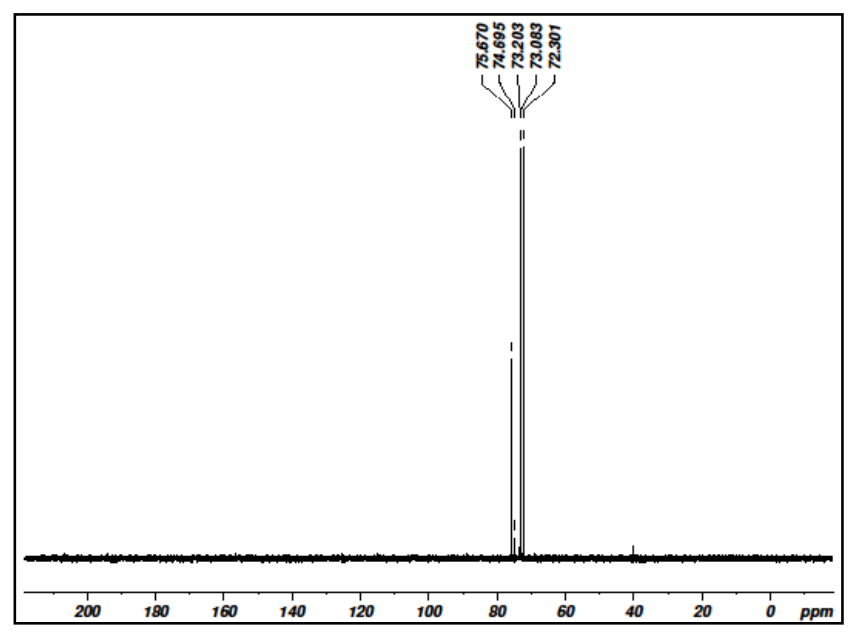

Figure 9 DEPT spectra of the N-cyclopent-1-enyl-hydroxylamine

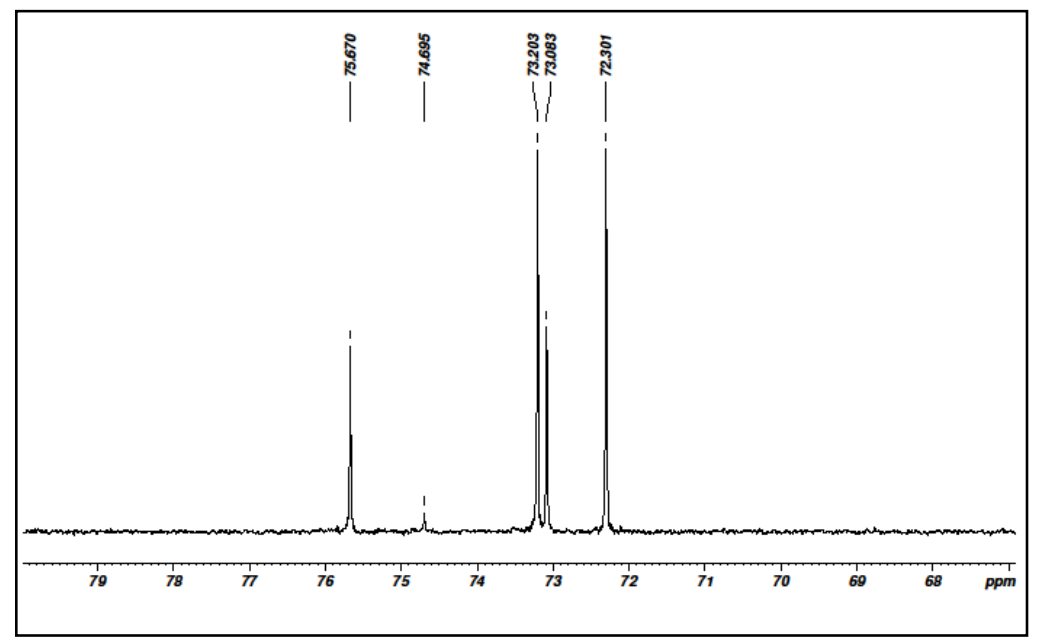

Figure 10 DEPT [Ex] spectra of the N-cyclopent-1-enyl-hydroxylamine 


\subsection{Anti microbial activities}

Fresh flowers of Cassia fistula and Santalum album were collected locally from Maruthamalai Hills, Tamil Nadu, India. The plant materials were identified and authenticated by. Botanical survey of India (BSI). The plant was washed carefully with running tap water, rinsed with distilled water and shade dried. They were ground into powder and stored in room temperature.

The dried leaf powder of $(50 \mathrm{~g})$ was successively extracted in soxhlet apparatus using hexane, ethyl acetate and methanol $(250 \mathrm{~mL}$ of each). The extracts were dried under reduced pressure using rotary vacuum evaporator to get the crude and were stored below $4^{\circ} \mathrm{C}$ until further use.

In vitro antimicrobial activity was examined for various alcoholic extract of bark of the study species against four bacterial species and four fungus which included Staphylococcus aureus, Bacillus subtilis, Escherichia coli and Pseudomonas aeruginosa and Staphylococcus aureus, Bacillus subtilis, Escherichia coli and Pseudomonas aeruginosa species respectively. All these microbial strains were obtained from the Department of Biotechnology, Kongunadu Arts and Science College. The bacterial stock cultures were maintained on nutrient agar slants and fungal stock culture maintained on Potato dextrose agar slant at $4^{\circ} \mathrm{C}$.

The isolated compound are screened for their in-vitro growth inhibitory action against different strains of bacteria viz., Staphylococcus aureus, Bacillus subtilis, Escherichia coli, Pseudomonas aeruginosa, the results are presented in Table - 1 and Figure 11. The compound shows a significant antibacterial activity against Staphylococcus aureus, Bacillus subtilis, Escherichia coli, Pseudomonas aeruginosa. All extract has been moderate activity compared to standard drugs of Tetracycline.

\subsection{Anti-fungal activity}

The in vitro antifungal activity of the compound and of tetracycles as the reference drug on a panel of fungi such as Aspergillus niger, A. flavus, A. baumanii, and Fusarium oxysporum measured as diameter of inhibition is provided in Table 2. Against all the fungal strains, isolated compound, exhibited antifungal activity against Fusarium oxysporum diameter of inhibition of $9.18 \pm 0.68$ in petroleum ether extract and methonal extract values $11.75 \pm 0.28$. Of isolated compound extract are found to be potent against Fusarium oxysporum, and Aspergillus niger showing of 9.23 $0.49 \& 15.79 \pm 0.66 \mu \mathrm{g} / \mathrm{ml}$ respectively, rest of the isolated compound extract were no effect potent against all the tested strains.
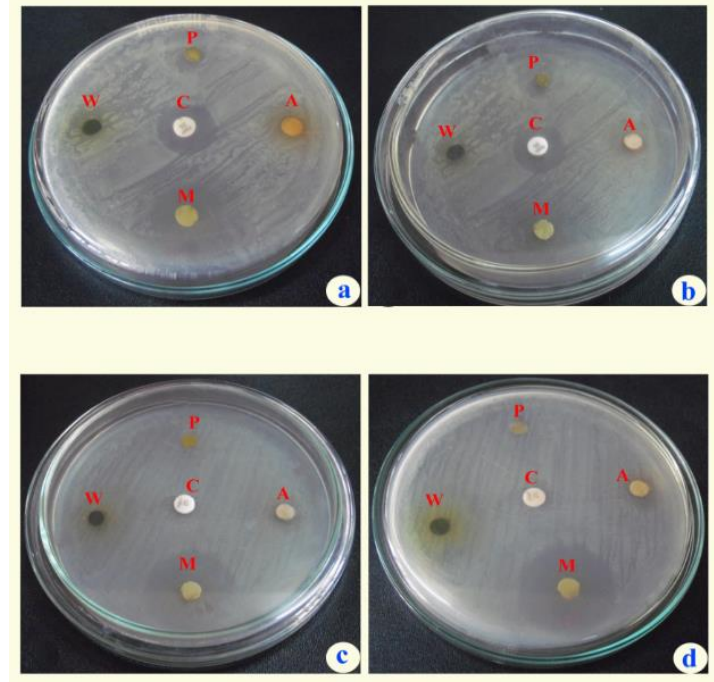

Figure 11 Anti microbial activity

\subsection{Molecular Docking studies}

The crystal structure of HIV integrase was obtained from proterin databank (PDB ID: 1HXW) with a resolution factor $\AA$. Before docking, the crystal structure of the protein was cleaned by removing the water molecule, added the hydrogen atom to the protein structure for tautomeric and ionization states of amino acid residues using OPLS-2005 forcew field. Finally the protein structure energy was minimized reached untill the average root mean square deviation non bonded hydrogen atom $0.30 \AA$. The prepared protein were input file for molecular docking .

The HIV protease (PDB ID: $1 \mathrm{HXW}$ ) was retrieved from protein data bank further taken to CASTp for binding site prediction which revealed different binding site. The best binding residues from the CASTp result given below. R8, 23L, 25D, 26T, 27G, 28A, 29D, 30D, V32, 47I, 48G,49G, 50I, R8, P9,L10, L23, D25, T26, G27, A28, D29, D30, P31, V32, 147, 48G, R87..

The isolated compound was drawnusing chem draw version ,. The ligand structure was further carried out into ligprep for ligand preparation version ,. Ligprep convert 3D structure from 2D structure, include different tautomers and ionized form at a $\mathrm{pH}$ range $7.0 \pm 2.0$. the prepared ligands were input file for molecular docking studies.

The isolated compound was docked in to the active site of the HIV protease (PDB ID: 1HXW) using Glide from Schrodinger 9.5. Grid was prepared for $p$ HIV protease with the exact same center and the size of the bounding box set on $20 \AA$. The Glide algorithm was based on a systematic search of positions, orientations, and conformations of the ligand in the receptor binding site using funnel type approach. 
The search begins with a rough positioning and scoring phase that significantly limits the search space and reduces the number of poses to be selected for minimization on the pre-computed OPLS-2005 van der Waals and electrostatic grids for the protein. The glide score and glide energy was analyzed using XP visualize Table-3.

3.8 Binding mode of isolated compound into HIV Proteas

Docking simulation of isolated compound within the active site of the HIV Protease has been analyzed. The Glide Score and Glide Energy value for compound was $-3.767 \mathrm{Kcal} / \mathrm{mol}$ and $-23.176 \mathrm{Kcal} / \mathrm{mol}$. Upon the examination of docking features between isolated compound and HIV protease. it was found only three hydrogen bond interaction with bond distance $(2.46 \AA$, $1.92 \AA, 2.16 \AA$ ).

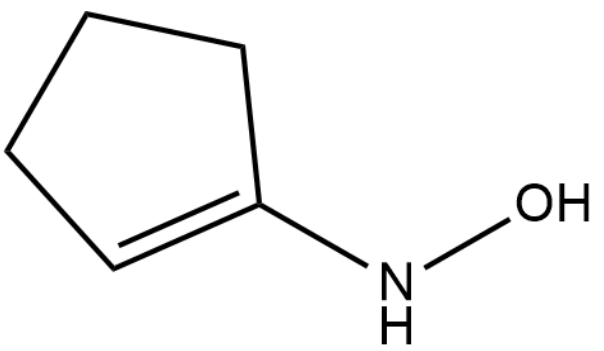

N-cyclopent-1-enyl-hydroxlamine

Table - 1 Antibacterial activity of certain alcoholic bark extracts of the species, Givotia rottlerifomis Griff

\begin{tabular}{|l|c|c|c|c|}
\hline \multirow{2}{*}{\multicolumn{1}{c|}{ Bacteria }} & \multicolumn{3}{|c|}{ Diameter of inhibition zone (mm) } \\
\cline { 2 - 5 } & $\begin{array}{c}\text { Standard } \\
\text { (Tetracycline) }\end{array}$ & Petroleum ether & Methanol & Water \\
\cline { 3 - 5 } & $8.13 \pm 0.57$ & $15.19 \pm 0.38$ & $14.16 \pm 0.56$ & $12.83 \pm 0.45$ \\
\hline $\begin{array}{l}\text { Staphylococcus } \\
\text { aureus }\end{array}$ & $9.03 \pm 0.45$ & $14.17 \pm 0.33$ & $15.23 \pm 0.71$ & $11.34 \pm 0.23$ \\
\hline Bacillus subtilis & $22.43 \pm 0.38$ & $10.71 \pm 0.55$ & $9.05 \pm 0.33$ & $10.56 \pm 0.33$ \\
\hline Escherichia coli & $23.03 \pm 0.54$ & $9.07 \pm 0.65$ & $10.11 \pm 0.45$ & $9.41 \pm 0.66$ \\
\hline $\begin{array}{l}\text { Pseudomonas } \\
\text { aeruginosa }\end{array}$ & & & & \\
\hline
\end{tabular}

Table - 2 Antifungal activity of certain alcoholic bark extracts of the species Givotia rottlerifomis Griff

\begin{tabular}{|l|c|c|c|c|}
\hline \multirow{2}{*}{ Fungi } & \multicolumn{3}{|c|}{ Diameter of inhibition zone (mm) } \\
\cline { 2 - 4 } & Standard & \multicolumn{2}{c|}{ Solvent extracts } \\
\cline { 2 - 4 } & (Tetracycline) & Petroleum ether & $15.79 \pm 0.66$ & $14.58 \pm 0.80$ \\
\hline Aspergillus niger & $33.22 \pm 0.58$ & $9.23 \pm 0.49$ & $14.18 \pm 0.63$ & $10.17 \pm 0.48$ \\
\hline A. flavus & $35.17 \pm 0.45$ & $10.13 \pm 0.25$ & $12.45 \pm 0.33$ & $12.85 \pm 0.78$ \\
\hline A. baumanii & $36.68 \pm 0.40$ & $8.38 \pm 0.48$ & $11.75 \pm 0.28$ & $12.69 \pm 0.27$ \\
\hline Fusarium oxysporum & $34.25 \pm 0.87$ & $9.18 \pm 0.68$ & \\
\hline
\end{tabular}


Thesidechain hydrogen atom of the negative charged residue of ASP 30 were strongly interacted with oxygen atom of the compound 4, compound 34 were strongly interacted withnegative charged residue of ASP 30. Furthermore ILE 47, ALA 28, ILE 50, LEU 76 a number of hydrophobic interactions was bound between compound 4 into IV Protease (Figure 12a-b).

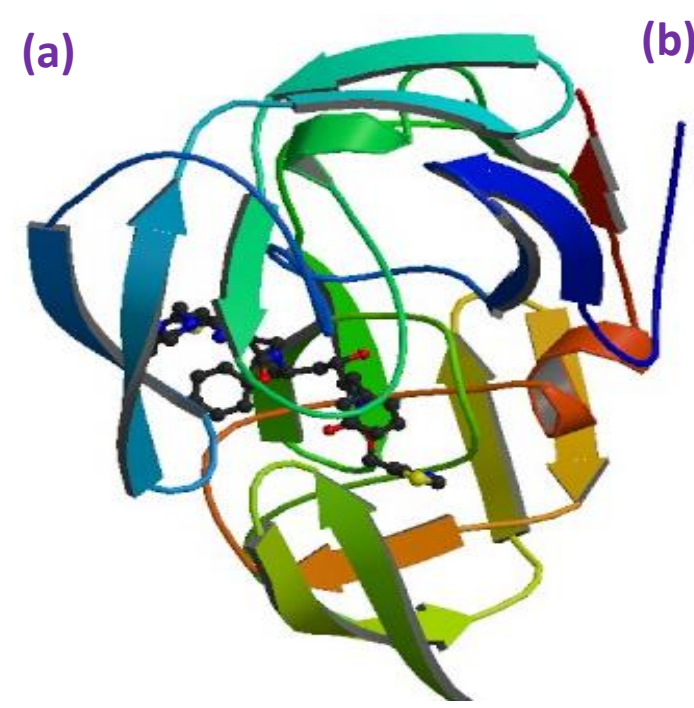

(b)

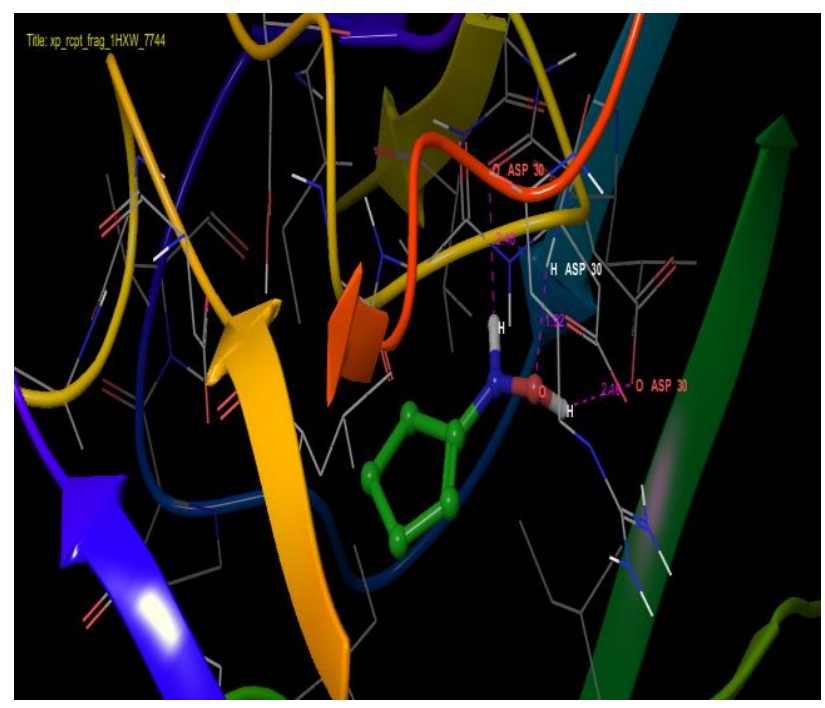

Figure 12 (a) 3-Dimensional Structure of Target Protease with protein HIV Protease (PDB ID: $1 \mathrm{HXW}$ ) (b) Docked structure of target protein HIV with $\mathrm{N}$-cyclopent-1-enyl-hydroxylamine

Table-3 Glide extra precision (XP) results isolated molecules by use Schrodinger-9.5

\begin{tabular}{|c|c|c|c|c|c|}
\hline $\begin{array}{c}\text { Compound } \\
\text { Name }\end{array}$ & Glide Score & Glide Energy & $\begin{array}{c}\text { No of H } \\
\text { bond } \\
\text { interactions }\end{array}$ & $\begin{array}{c}\text { Interacting } \\
\text { Residue }\end{array}$ & $\begin{array}{c}\text { Distance } \\
(\AA)\end{array}$ \\
\hline $\begin{array}{c}\text { Givotia } \\
\text { rottleriformis griff }\end{array}$ & -3.767 & -23.176 & 3 & $\begin{array}{c}\text { ILE 50 } \\
\text { ILE 50 }\end{array}$ & 2.461 .92 \\
ILE 50 & 2.16 \\
\hline
\end{tabular}

\section{Conclusion}

In conclusion, this study is a complementary survey to phytochemical and spectral studies carried out upon $\mathrm{N}$-cyclopent-1-enyl-hydroxlamine. This project work involves bark extraction of the givotia rottleriformis griff with petroleum ether from which a pure component has been identified by crystallization with benzene. TLC report also gives the indication of a pure component. Melting point determination, IR, 1H-NMR, 13C-NMR and 2D-NMR spectral techniques identify the purity of the compound and also the spectral data's indicate that the compound is tentatively $\mathrm{N}$-cyclopent-1-enylhydroxylamine. Further pharmacological studies like Anti-microbial, and anti-fungal activities studies are required to find out the complete physiological and pharmacological action of the compound.
So that identified compound may be correctly predicted as $\mathrm{N}$-cyclopent-1-enyl- hydroxylamine. Thus, our method, reported here is found to give moderate yield of a compound likely to be $\mathrm{N}$-cyclopent-1-enylhydroxylamine of fairly pure quality. This is a very rapid, straight forward and new innovative method of extraction of the olefilic compounds, N-cyclopent-1enyl- hydroxylamine from the bark of givotia rottleriformis griff. Docking simulation of isolated compound within the active site of the HIV Protease has been analyzed. The Glide Score and Glide Energy value for compound was $-3.767 \mathrm{Kcal} / \mathrm{mol}$ and $23.176 \mathrm{Kcal} / \mathrm{mol}$. 


\section{References}

[1] S. Cutler, H.G. Cutler, (2000) Biologically Active Natural Products: Pharmaceuticals, CRC Press. pg. 5.

[2] G. Samuelson, (1999) Drugs of Natural Origin: A Textbook of Pharmacognosy. Taylor \& Francis Ltd.

[3] D.A. Williams, T.L. Lemke, (2002) "Chapter 1: Natural Products". Foye's Principles of Medicinal Chemistry (5th ed.). Philadelphia: Lippincott Williams Wilkins. p. 25.

[4] R.A. Maplestone, M.J. Stone, D.H. Williams, The evolutionary role of secondary metabolites-a review, Gene, 115(1-2) (1992) 151-157. https://doi.org/10.1016/0378-1119(92)90553-2

[5] P. Hunter, Harnessing Nature's wisdom. Turning to Nature for inspiration and avoiding her follies, EMBO Reports, 9(9) (2008) 838840. https://dx.doi.org/10.1038/embor.2008.160

[6] J.W. Li, J.C. Vederas, Drug discovery and natural products: end of an era or an endless frontier?, Science, 325 (5937) 161-165. https://doi.org/10.1126/science.1168243

[7] S.V. Bhat, B.A. Nagasampagi, M. Sivakumar, (2005) Chemistry of Natural Products. Berlin; New York: Springer.

[8] D.J. Kliebenstein, Secondary metabolites and plant/environment interactions: a view through Arabidopsis thaliana tinged glasses, Plant, Cell and Environment. 27 (6) (2004) 675-684. https://doi.org/10.1111/j.1365-

3040.2004.01180.x

[9] K. Rogers, (2011) The Components of Life: From Nucleic Acids to Carbohydrates (1st ed.). New York, NY: Britannica Educational Publishing in association with Rosen Educational Services.

[10] D.L. Cox, M.M. Nelson, (2013), Lehninger Principles of Biochemistry (6th ed.). New York, N.Y.: W.H. Freeman.

[11] D. Boal, (2006) Mechanics of the Cell (4th printing ed.). Cambridge, UK: Cambridge University Press.

[12] P.M. Dewick, (2009) Medicinal Natural Products: A Biosynthetic Approach (3rd ed.). Chichester: Wiley.

[13] A. Sitaramayya, (1999), Introduction to Cellular Signal Transduction. Boston: Birkhäuser.

[14] A.L. Demain, A. Fang, The natural functions of secondary metabolites, Advances in Biochemical Engineering / Biotechnology, 69 (2000) 1-39. https://doi.org/10.1007/3-54044964-7 1

[15] D.H. Williams, M.J. Stone, P.R. Hauck, S.K. Rahman, Why are secondary metabolites (natural products) biosynthesized?, Journal of Natural Products. 52 (6) (1989) 1189-208. https://doi.org/10.1021/np50066a001

\section{Funding}

No funding was received for conducting this study.

\section{Conflict of interest}

The authors have no conflicts of interest to declare that they are relevant to the content of this article.

\section{Author's contribution}

Both the authors equally contributed to this work.

\section{About the License}

(C) The author(s) 2021. The text of this article is open access and licensed under a Creative Commons Attribution 4.0 International License

\section{Cite this Article}

V. Mohanraj, R.V. Sakthivel, M. Karthick, R. Velmurugan, Phytochemical and biological investigation of Indian medicinal plant of givotia rottlerifromis griff, International Research Journal of Multidisciplinary Technovation, 3(2) (2021) 54-63. DOI: https://doi.org/10.34256/irjmt2129 